Original Research Paper

\title{
Study on Danger Index for Ship's Tanker
}

\author{
Muhammad Badrus Zaman and Semin \\ Department of Marine Engineering, Institut Teknologi Sepuluh Nopember, Surabaya 60111, Indonesia
}

\author{
Article history \\ Received: 12-11-2016 \\ Revised: 07-01-2017 \\ Accepted: 13-04-2017 \\ Corresponding Author: \\ Semin \\ Department of Marine \\ Engineering, Faculty of Marine \\ Technology, Institut Teknologi \\ Sepuluh Nopember, Surabaya \\ 60111, Indonesia \\ Email: seminits@yahoo.com
}

\begin{abstract}
Navigational safety is an important factor for the ship navigation. In this research, the study area is the Malacca Strait. The Malacca Straits has a high level of danger. The navigator should be careful when passing through the strait. Based on the survey, about $85 \%$ of the navigator was worried when passing through the area of Straits. Automatic Identification System (AIS) data investigation was conducted on August 2012. Tanker passes through the Malacca Strait about $45 \%$ per day. This study focused on the analysis of danger index in Tanker. Results from this study can be used as input to all stakeholders to improve safety while Tanker passes through the Malacca Strait. Scenario for establishing danger Index is taken from the AIS data which is installed in the UTM Malaysia. In detail, danger index was calculated using Analytic Hierarchy Process (AHP) combining with the Automatic Identification System (AIS) data and Geographic Information System (GIS).
\end{abstract}

Keywords: Danger Index, Tanker, AIS Data, Malacca Straits

\section{Introduction}

Ship safety of navigation is very important in the maritime issue. Malacca Straits is busy area in the world. It has a very strategic area in the shipping activities and international trade which was connect countries in West Asia, South East Asia and East Asia.

It also was classified as danger area. Navigators should take carefully when navigate the ship. They should know the hazard map in that area. Research on investigation of danger in this area is very interesting to do. The results of the safety index or danger score is very important to inform the crew of ship to be more careful and prioritize safety while sailing.

\section{Literature Review}

Enhancing maritime safety is one of the main concerns of marine ship navigation. Based on International Maritime Organization (IMO) recommendation, implementation of an Automatic Identification System (AIS) should give benefit for safety on the ship and environment.

Malacca Strait is a sea border (sea borderlines) Indonesia, Malaysia and Singapore. The strait is one of the vital shipping lanes in the world and one of nine straits and strategic waterway in the world (Thia-Eng et al., 2000).
Strait, annually estimated crossed by approximately 70 thousand ships or approximately 150-200 ships per day. Some of them are tankers of 180,000 DWT or more, which transports more than $40 \%$ of goods trade country in the world, with trade volume reaching 19245.7 million tons per year with an average rise of $4.3 \%$ per year. That does not include petro product amounted to 15.2 million barrels per day. Half of the world's oil is transported through this strait to the amount of about 11 million barrels of oil per day, mainly from the Middle East to Japan, China and South Korea. Malacca Strait is the closest trajectory of the Indian Ocean to the Pacific (Zaman et al., 2013).

In this study, an Automatic Identification System (AIS) was used to study danger index model of a tanker in the Malacca Straits. In this case, result of investigation of AIS was used to analyze the traffic density and ship population in the area. AHP method used to make criteria that contributed the accident in the straits.

\section{Automatic Identification System Installation}

Hazard identification of tanker ships using AIS in the Malacca Straits is an important step of the risk assessment. All factors that contribute the accident should be identified, AIS installation was helping to get data of hazard. 
Figure 1 shows the area study and result of ship tracing using AIS and GIS. This is very useful to determine danger index. Figure 2 shows installation of AIS. AIS receiver has installed at Universiti Teknologi Malaysia (UTM) Malaysia.

Based on AIS data in Fig. 3, tankers have the largest portion of the ship population at $45 \%$.

Figure 4 shows the tanker ship classification based on AIS data. AIS application installed to provide facilities for communication between the ship to ship and ship to the harbor. Thus the safety can be improved. Based on statistical data on type of vessels for 1978-1994, the type of accident in the Strait of Malacca could be identified. The highest numbers are general cargos $(53.15 \%)$, second are tankers $(20.59 \%)$. The types of casualties are (1) fire explosions, (2) stranded/grounded, (3) sprung leaks, (4) collisions and (5) other (Arslan, 2009).

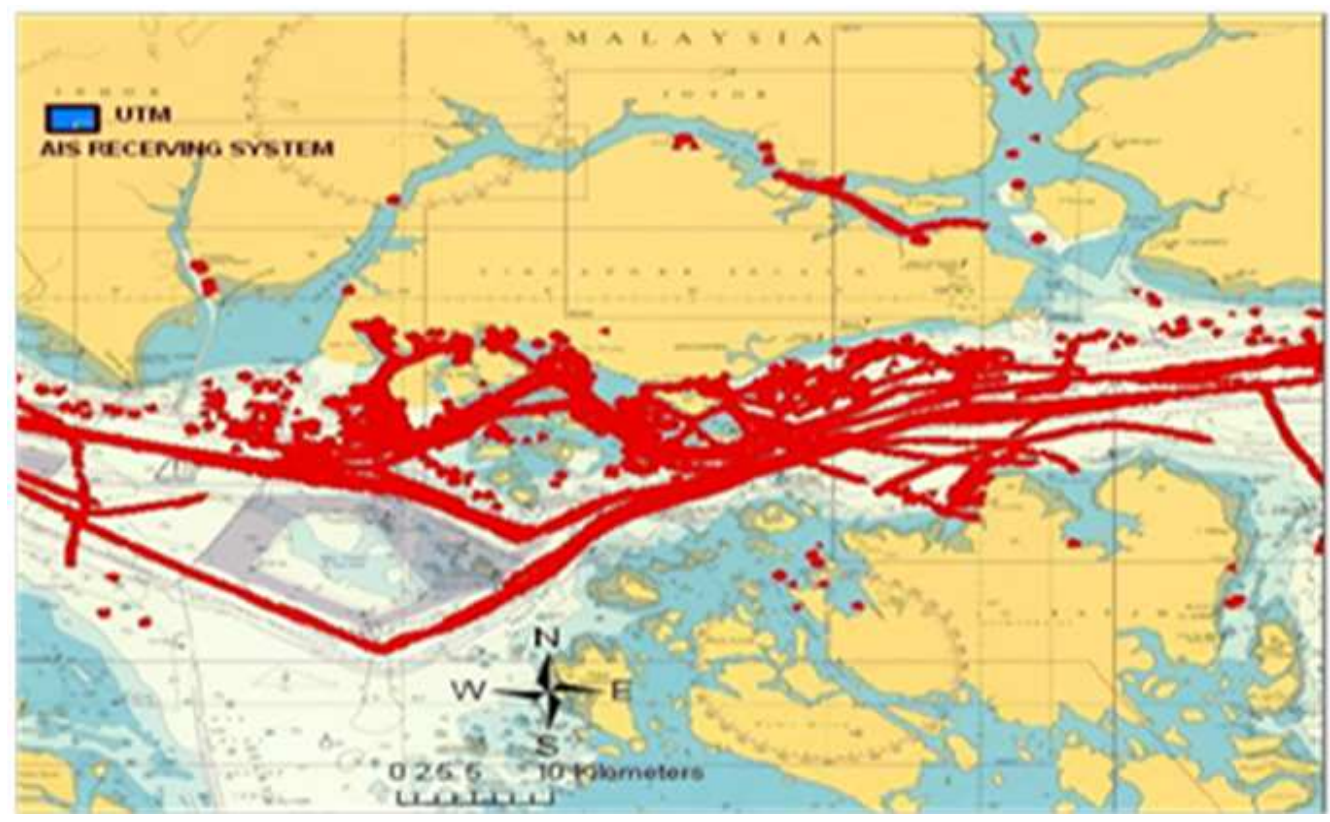

Fig. 1. Malacca straits area

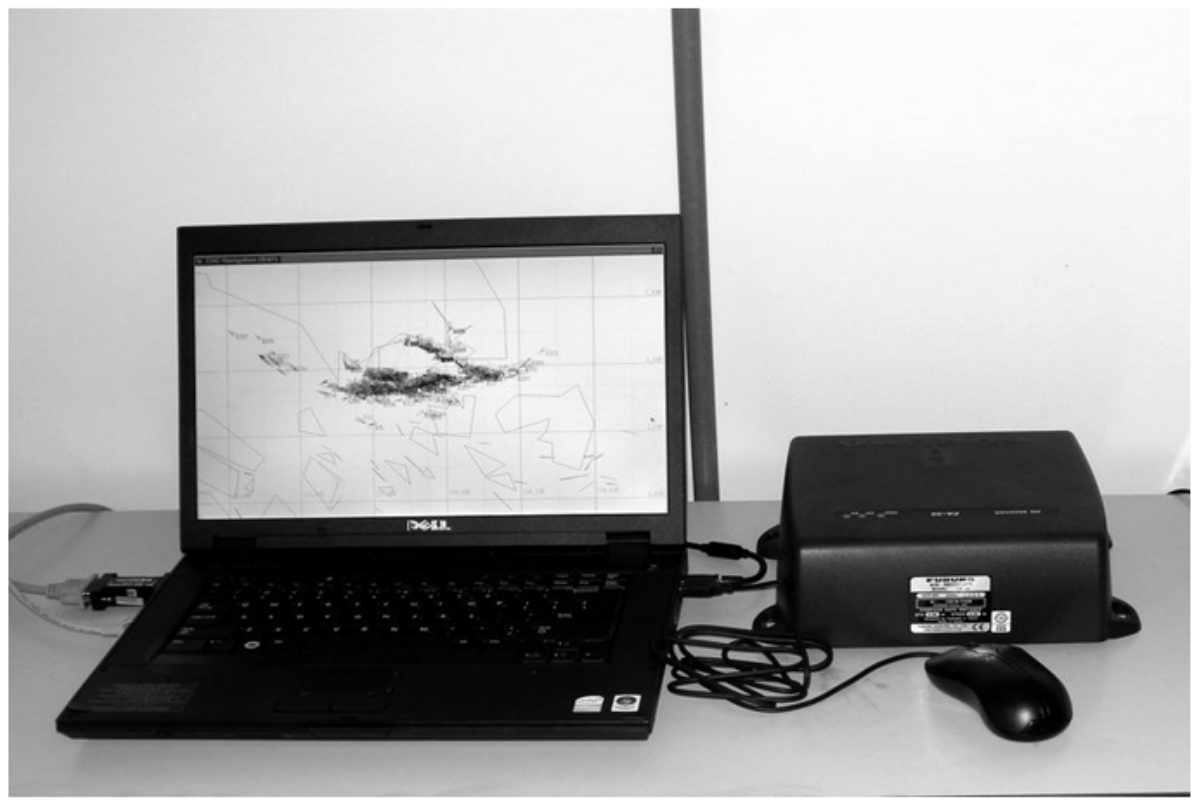

Fig. 2. Installation of AIS receiver 


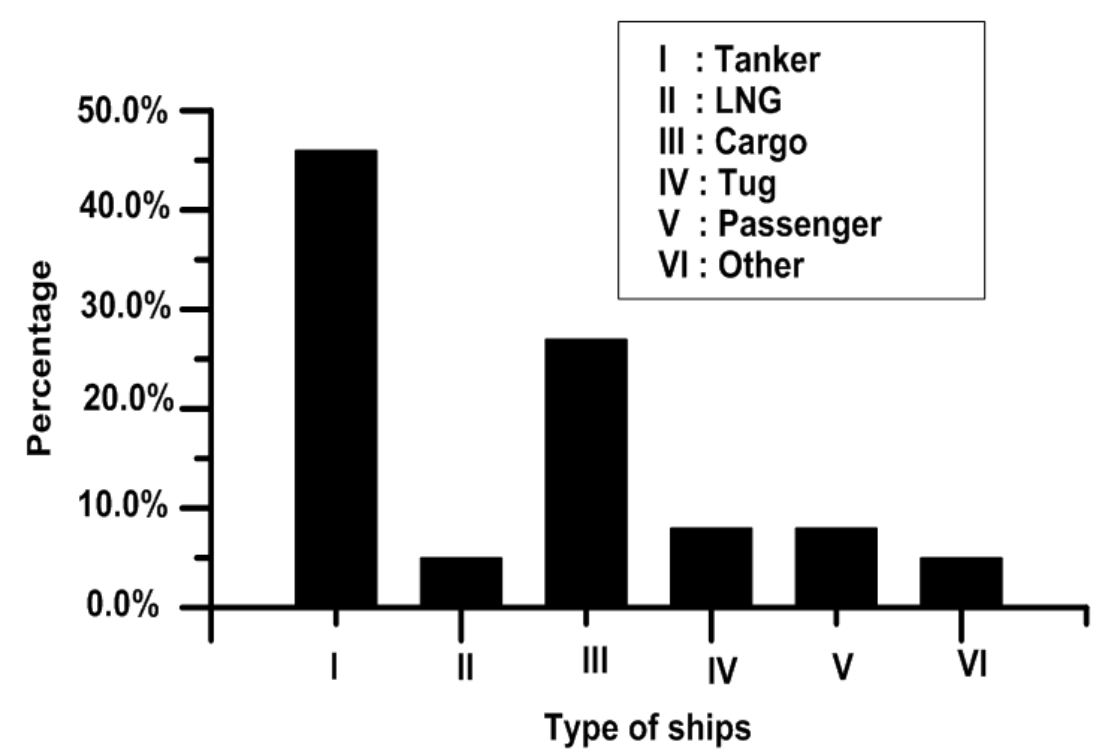

Fig. 3. Population of ship based on AIS

\section{TANKERSHIPS}

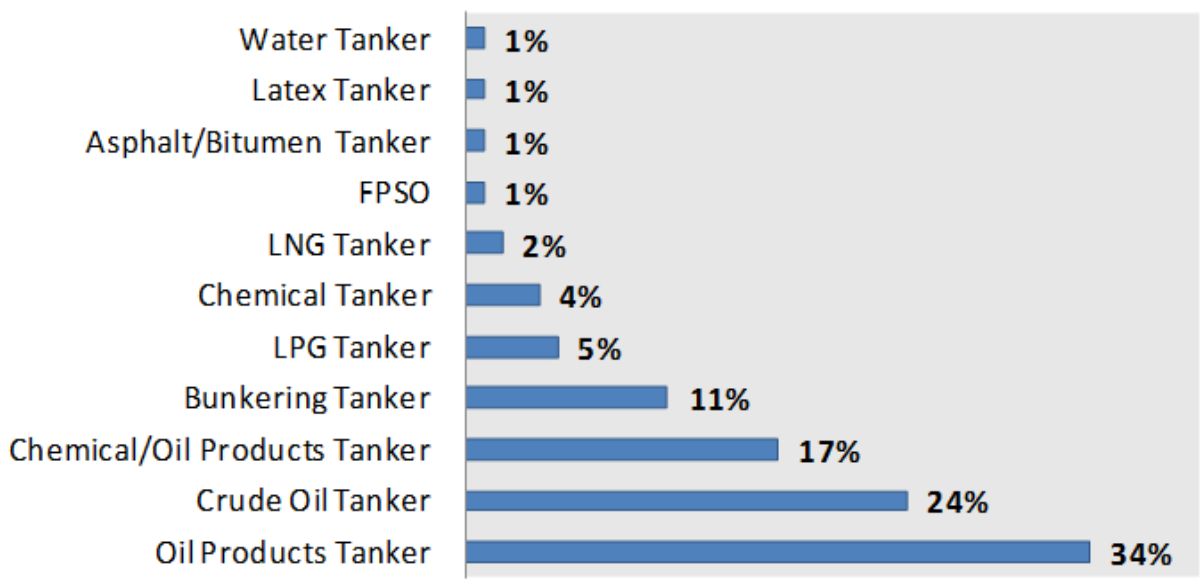

Fig. 4. Tanker ship classification based on AIS

Table 1. Pairwise comparison scale of AHP (Heck, 2011)

\begin{tabular}{ll}
\hline Point & Meaning \\
\hline 1 & Indifferent \\
3 & Weak preference (moderately more important) \\
5 & Preference (more important) \\
7 & Strong preference (strongly more important) \\
9 & Very strong preference (extremely more important) \\
$2,4,6$ and 8 & intermediate values \\
\hline
\end{tabular}

\section{Analytic Hierarchy Process}

AHP method used to establish criteria that contributed the accident in The Malacca Straits. Weighting criteria used for calculating danger index.
Table 1 shows a nine-point pairwise comparison scale typically used in the AHP.

The questionnaire has been conducted based on the structure of AHP. In this case, respondents who are selected to fill out the questionnaire were navigators 
and other crewmembers of ships that have knowledge and experience of passing through the Malacca Straits.

\section{Establishment of a Comparison Matrix}

In this step, the results of the questionnaire are calculated in a comparison matrix. The matrix was expressed by Equation 1:

$$
A=3\left[\begin{array}{ccccc}
w_{1} / w_{1} & w_{1} / w_{2} & w_{1} / w_{3} & \cdots & w_{1} / w_{n} \\
w_{2} / w_{1} & w_{2} / w_{2} & w_{2} / w_{3} & \cdots & w_{2} / w_{n} \\
w_{3} / w_{1} & w_{3} / w_{2} & w_{3} / w_{3} & \cdots & w_{3} / w_{n} \\
\vdots & \vdots & \vdots & \cdots & \vdots \\
w_{n} / w_{1} & w_{n} / w_{2} & w_{n} / w_{3} & \cdots & w_{n} / w_{n}
\end{array}\right]
$$

\section{Priority Vector}

Having a comparison matrix, we can compute the priority vector (in Equation 2), which is the normalized eigenvector of the matrix. So, in order to obtain the relative weights can be obtained from the rows in the matrix $A$ (Gran, 1999). Below is formula for the matrix $A$ :

$A^{*} W=n^{*} W$

where, $W$ was described as $\left(w_{1}, w_{2}, . ., w_{n}\right)$. Definition of $T$ is the vector for actual relative weight and $n$ is defined as element's numbers.

For the matrix of algebra, $W$ and $n$ in Equation 2 were defined as eigenvector and eigenvalue of matrix $A$.

In AHP, it is not easy to know $W$, therefore, is not able to produce the pairwise relative weights of matrix $A$ accurately. Calculation of $W$ could be described as follow:

$$
A^{*} W=\lambda_{\max } * W
$$

where, $A$ is described as matrix of pairwise comparisons, $\lambda_{\max }$ is the largest eigenvalue $W$ is its right eigenvector (Gran, 1999).

\section{Consistency Index and Consistency Ratio}

Consistency should be tested so that consistency can be achieved. CI values can be obtained from the following equation:

$$
C I=\left(\lambda_{\max }-n\right) /(n-1)
$$

The above equation explains that $C I$ is the consistency index, while $\lambda_{\max }$ explain the main eigenvalues of matrix, $\mathrm{n}$ expressed as a sequence of matrix. Then, the Consistency Ratio (CR) is calculated as follows:

$C R=C I / R I \leq 0.1$

where, $R I$ is average of the resulting consistency index depending on the order of the matrix. Value consistency should be less than 0.10 . It shows fairness. If the value of consistency is more than 0.10 , the matrix must be changed.

\section{Analytic Hierarchy Process Design and Application}

In this step, structure of AHP is designed. Based on hierarchy structure of AHP and having a comparison matrix, we can compute the priority vector, which is the normalized eigenvector of the matrix. AHP structure should be prepared as best as possible. In AHP, Goal should be set at the highest level, followed by sub-criteria, sub-criteria. In subcriteria should give to the second level which provides an explanation of the hierarchy.

Table 2. Evaluation of Criteria

\begin{tabular}{lllllll}
\hline Code & Criteria & SC & HF & EF & MF & MM \\
\hline SC & Ship Condition & 1.00 & 0.33 & 5.00 & 1.00 & 3.00 \\
HF & Human Factor & 3.03 & 1.00 & 3.00 & 1.00 & 3.00 \\
EF & Environmental Factor & 0.20 & 0.33 & 1.00 & 0.33 & 1.00 \\
MF & Machinery Factor & 1.00 & 1.00 & 3.03 & 1.00 & 1.00 \\
MM & Management Factor & 0.33 & 0.33 & 1.00 & 1.00 & 1.00 \\
TOTAL & 5.56 & 3.00 & 13.03 & 4.33 & 9.00 & \\
\hline
\end{tabular}

Table 3. Weight of main criteria

\begin{tabular}{lll}
\hline Code & Sub criteria & W \\
\hline CS & Condition of ship & 0.25 \\
PH & Problem of human & 0.33 \\
FE & Factor of environment & 0.08 \\
FEM & Factor of electricity and machinery & 0.22 \\
FM & Factor of management & 0.12 \\
\hline
\end{tabular}


Table 4. Weight of ship condition

\begin{tabular}{llr}
\hline Code & Sub criteria & W \\
\hline TS & Type of ship & 0.37 \\
L & Length & 0.12 \\
S & Speed & 0.38 \\
SL & State of loading & 0.12 \\
\hline
\end{tabular}

Table 5. Weight of human factors

\begin{tabular}{llr}
\hline Code & Sub criteria & W \\
\hline C & Communication & 0.15 \\
KS & Knowledge and skill & 0.38 \\
E & Experience & 0.29 \\
OW & Over worked & 0.11 \\
F & Fatigue & 0.07 \\
\hline
\end{tabular}

Table 6. Weight of environment factors

\begin{tabular}{lll}
\hline Code & Sub criteria & W \\
WE & wind effect & 0.19 \\
CE & current influence & 0.14 \\
SO & speed different against another ship & 0.10 \\
LO & vessel's length of other ship & 0.09 \\
TH & relationship between depth and waterline & 0.11 \\
DS & distance between vessels & 0.13 \\
CS & course of own ship and other ship's course & 0.11 \\
ZT & Zone of time & 0.03 \\
D & influence upon day and week & 0.03 \\
A & characteristic of the area & 0.08 \\
\hline
\end{tabular}

Table 7. Weight of environment factors

\begin{tabular}{lll}
\hline Code & Sub criteria & W \\
\hline IR & Problem of ship's operation management and regulation & 0.45 \\
IC & Problem of crew manning & 0.23 \\
IN & Problem of navigation & 0.32 \\
\hline
\end{tabular}

Table 2-7 shows the weight of sub criteria on ship condition, human factors, environmental factors, machinery factors and management factors.

\section{Result of Danger Index}

To increase safety and make comfortable for ship safety navigation, an evaluation index of ship navigational safety was compiled to make the levels more certain and accurate using AIS data. The process of the calculation is as follow:

First, the weight of each evaluation index is established by the AHP method. Second, the value of the function is determined based on AIS data $(\mathrm{Ou}$ and Zhu, 2008).

Implementation of AIS for determining danger index is very important to enhance safety index. By using equation below, danger index could be established:

$D I=\sum_{i=1}^{n} W_{i} f_{i}$ where, $D I$ is danger index, $\mathrm{f}$ is defined as fungtion for the each index, $w$ is defined as weight on index and $\mathrm{n}$ is defined as total number, $i$ is $1,2,3, \ldots \ldots ., n$ (Ou and Zhu, 2008).

Below is the resulting calculation of the danger score for a tanker that passed through the Malacca Straits on $01 / 06 / 2012$ at 16.00 . The ship data are given in Table 8 .

Table 8 shows the data of the ship. The calculation and simulation of the danger index have been established. The data were gathered in one hour. In this case, data were gathered on $01 / 06 / 2012$ at 16.00 h. Based on AIS data, we find the largest volume of data is at $16.00 \mathrm{~h}$. Figure 5 shows the tracking of a tanker ship on $01 / 06 / 2012$ at $16.00 \mathrm{~h}$. The resulting danger index are shown in Fig. 6, where the danger was highest on 16.08.06.

In similar way, we could determine danger score in different location in the Malacca Straits. We also could simulate with different time and different ship. 


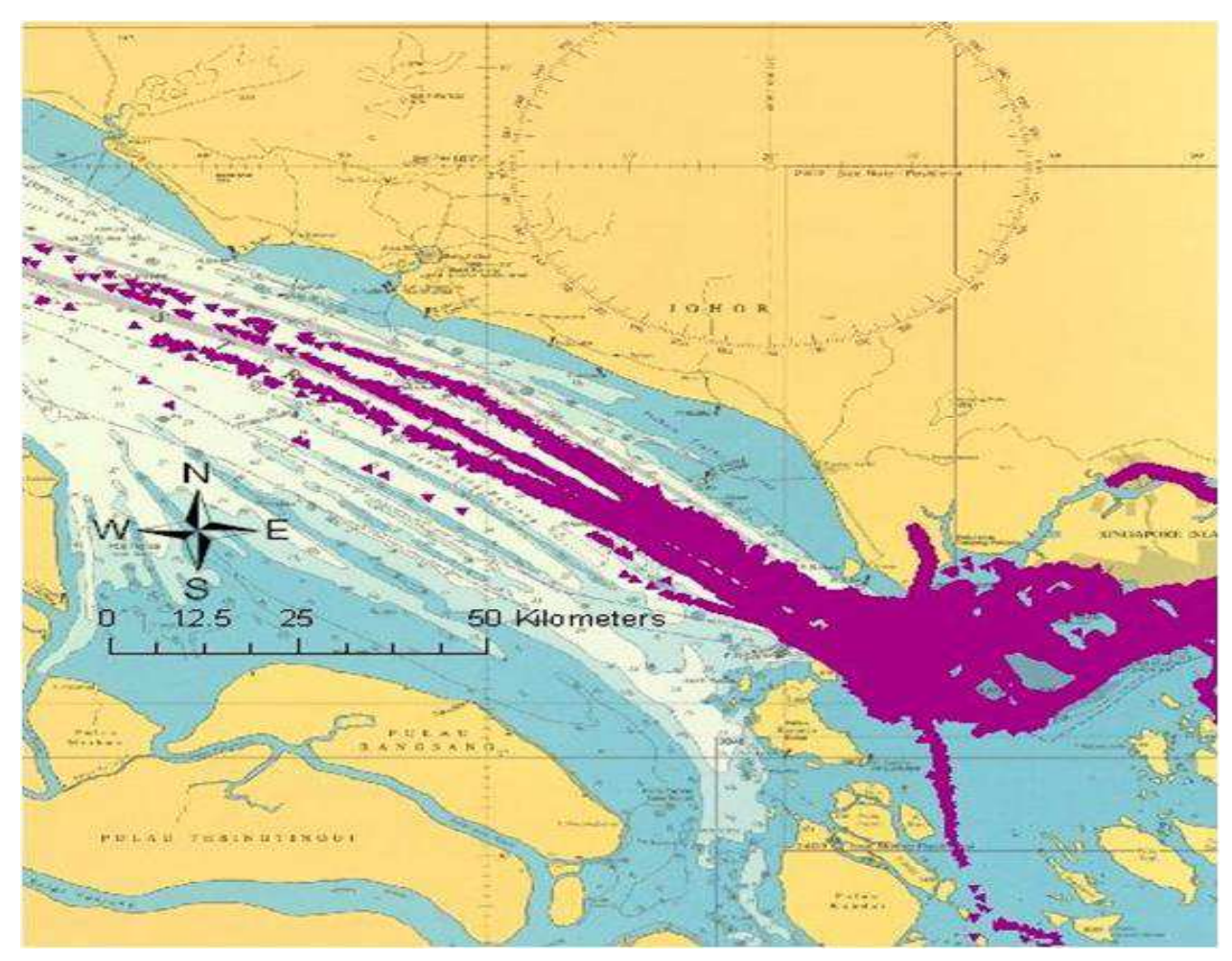

Fig. 5. Danger index area of tanker

\section{DS vs Time}

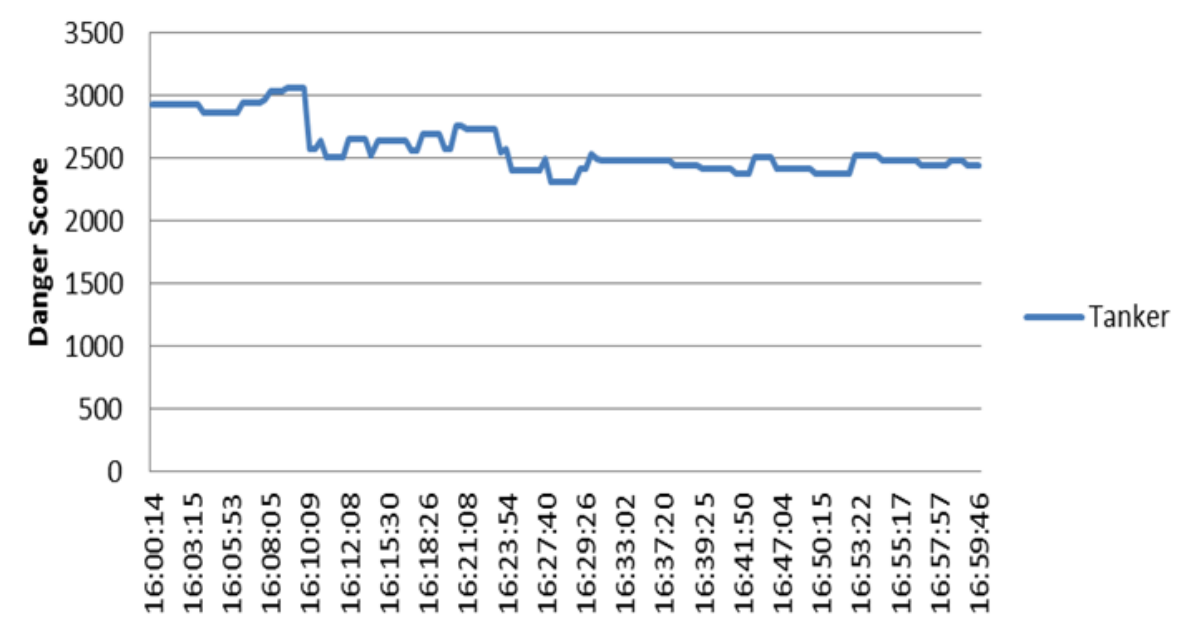

Fig. 6. Danger index for tanker ship on $1 / 06 / 2012$ at $16.00 \mathrm{~h}$

Table 8. Ship data

\begin{tabular}{ll}
\hline Name of ship & Titan neptune \\
\hline Ship type & Tanker \\
LOA $(\mathrm{m})$ & 322 \\
Total tonnage $(\mathrm{t})$ & 265243 \\
Speed (knot) & 15 \\
Flag & Panama \\
MMSI & 354223000 \\
\hline
\end{tabular}

\section{Conclusion}

This paper presents an establishing danger index for tanker ship in the Strait of Malacca. By using AHP, several factors that contribute to accidents in the Malacca Straits were explored. The leading criteria that contribute to accidents in the Malacca Straits are human factors. 
Investigation using AIS in the Mallacca Straits area was conducted. Type of vessels on 01/06/2012 was investigated. The classification are: Tanker vessels $45 \%$, cargo vessels arround $26 \%$, tug vessels $9 \%$, passenger vessels $9 \%$, LNG $5 \%$ and other vessels $6 \%$.

In this research, an analysis of danger score has conducted using AIS data. Figure 5 shows the tracking of a tanker ship on $01 / 06 / 2012$ at 16.00 . The result of danger index is shown in Fig. 6, in which the danger was highest on 16.08.06.

\section{Acknowledgment}

The authors wish to thank to Prof Semin and all members of the Marine Opeartion and Maintenance System Laboratory at ITS Surabaya for their support in the discussion and analysis of the data.

\section{Funding Information}

The author also wish to thank to Professor Semin which has given me the information to contribute and submite to this Journal.

\section{Author's Contributions}

Muhammad Badrus Zaman: Prepare for all article data and row materials.

Semin: Edit the report for article

\section{Ethics}

This article is original and contains unpublished material. The corresponding author confirms that all of the other authors have read and approved the manuscript and no ethical issues involved.

\section{References}

Arslan, O., 2009. Analytical investigation of marine casualties at the Strait of Istanbul with SWOT-AHP method. Maritime Policy Manage., 36: 131-145. DOI: 10.1080/03088830902868081

Gran, S., 1999. The impact of transportation on Widlife in the Malacca straits. TED Case Stud., 9: 573-573.

Heck, N., 2011. Stakeholders' expectations towards a proposed marine protected area: A multi-criteria analysis of MPA performance criteria. Ocean Coastal Manage., 54: 687-695.

DOI: 10.1016/j.ocecoaman.2011.07.003

$\mathrm{Ou}, \mathrm{Z}$. and J. Zhu, 2008. AIS database powered by GIS technology for maritime safety and security. J. Navigat., 61: 655-651. DOI: $10.1017 / \mathrm{S} 0373463308004888$

Thia-Eng, C., I.R.L. Gorge and S.A. Ross, 2000. The Malacca straits. Marine Pollut. Bull, 41: 160-178. DOI: 10.1016/S0025-326X(00)00108-9

Zaman, M.B., E. Kobayashi, N. Wakabayashi, T. Pitana and A. Maimun, 2013. Implementation of Automatic Identification System (AIS) for evaluation of marine traffic safety in strait of Malacca using Analytic Hierarchy Process (AHP). J. Japan Society Naval Arch. Ocean Eng., 16: 141-153. DOI: $10.2534 /$ jjasnaoe.16.141 